Article

\title{
Impact of GSTA1 Polymorphisms on Busulfan Oral Clearance in Adult Patients Undergoing Hematopoietic Stem Cell Transplantation
}

\author{
Veronique Michaud ${ }^{1,2}$, My Tran ${ }^{3}$, Benoit Pronovost ${ }^{1}$, Philippe Bouchard ${ }^{1,4}$, Sarah Bilodeau ${ }^{1,4}$, \\ Karine Alain ${ }^{1,4}$, Barbara Vadnais ${ }^{1,4}$, Martin Franco ${ }^{1,4}$, François Bélanger ${ }^{2}$ and \\ Jacques Turgeon ${ }^{1,2, *}$ \\ 1 Faculty of Pharmacy, Université de Montréal, Montreal, QC H3C 3J7, Canada \\ 2 CRCHUM, Centre de Recherche du Centre Hospitalier de l'Université de Montréal, Montreal, \\ QC H2X 0A9, Canada \\ 3 College of Pharmacy, Lake Nona Campus, University of Florida, Orlando, FL 32827, USA \\ 4 Hôpital Maisonneuve-Rosemont, Montreal, QC H1T 2M4, Canada \\ * Correspondence: jturgeon@trhc.com; Tel.: +01-856-938-8793
}

Received: 9 July 2019; Accepted: 18 August 2019; Published: 1 September 2019

\begin{abstract}
Background: Busulfan pharmacokinetics exhibit large inter-subject variability. Our objective was to evaluate the influence of glutathione S-transferase A1 (GSTA1) gene variants on busulfan oral clearance (CLo) in a population of patients undergoing hematopoietic stem cell transplantation. Methods: This is a quasi-experimental retrospective study in adult patients $(n=87$ included in the final analyses) receiving oral busulfan. Pharmacokinetics data (area under the plasma concentration-time curve (AUC) determined from 10 blood samples) were retrieved from patients' files and GSTA1 ${ }^{*} A$ and ${ }^{*} B$ allele polymorphisms determined from banked DNA samples. Three different limited sampling methods (LSM) using four blood samples were also compared. Results: Carriers of GSTA1* $B$ exhibited lower busulfan CLo than patients with an ${ }^{*} A{ }^{*} A$ genotype $(p<0.002)$ : Busulfan CLo was $166 \pm 31,187 \pm 37$ vs. $207 \pm 47 \mathrm{~mL} / \mathrm{min}$ for $G S T A 1^{*} B{ }^{*} B,{ }^{*} A{ }^{*} B$ and ${ }^{*} A{ }^{*} A$ genotypes, respectively. Similar results were obtained with the tested LSMs. Using the standard AUC method, distribution of patients above the therapeutic range after the first dose was $29 \%$ for $G S T A 1^{*} A{ }^{*} A, 50 \%$ for ${ }^{*} A{ }^{*} B$, and $65 \%$ for ${ }^{*} B{ }^{*} B$. The LSMs correctly identified $\geq 91 \%$ of patients with an AUC above the therapeutic range. The misclassified patients had a mean difference less than $5 \%$ in their AUCs. Conclusion: Patients carrying GSTA1 loss of function ${ }^{*} B$ allele were at increased risk of overdosing on their initial busulfan oral dose. Genetic polymorphisms associated with GSTA1 explain a significant part of busulfan CLo variability which could be captured by LSM strategies.
\end{abstract}

Keywords: busulfan; glutathione S-transferase; genetic polymorphism; limited sampling strategy; pharmacokinetics

\section{Introduction}

In current hematopoietic stem cell transplantation (HSCT) practices, busulfan is a commonly used alkylating agent. When combined with other drugs, busulfan exhibits a beneficial immunosuppressive effect [1]. The drug has a very narrow therapeutic index which requires close therapeutic monitoring. Low concentrations of busulfan can result in an increased risk of graft failure and recurrence of the disease whereas high concentrations of busulfan can result in an increased risk of hepatic toxicity $[2,3]$. Current therapeutic monitoring methods of the drug involve taking numerous (often up to 10) blood samples to calculate patient's plasma concentration vs. time area under the curve (AUC) [4]. However, 
we and others have demonstrated the value of limited sampling strategies to estimate mean busulfan plasma concentration and compute required busulfan doses in these leukemic patients [5-9].

The glutathione S-transferase enzymes (GSTs) are important Phase II biotransformation enzymes that catalyze the conjugation of many hydrophobic and electrophilic compounds with reduced glutathione [10,11]. Based on their biochemical, immunologic, and structural properties, soluble GSTs (including cytosolic and mitochondrial forms) are divided into several classes; alpha, mu, kappa (mitochondrial), theta, pi, omega, and zeta [10,11]. The GST alpha 1 (A1) isoform is mainly expressed in the liver, intestine, kidneys and endocrine tissues and contributes to the metabolism of several anticancer drugs as well as steroids and products of lipid degradation [12,13]. The GSTA1 gene has been mapped to the GST-alpha gene cluster on chromosome $6 \mathrm{p} 12$, it is approximately $12 \mathrm{~kb}$ long and contains seven exons [14]. GSTA1 expression is influenced by a genetic polymorphism that consists of two alleles, GSTA1*A and GSTA1*B, containing three linked base substitutions in the proximal promoter, at positions $-567,-69$, and -52 [14,15]. The $G$-to- $A$ change at position -52 appears to be responsible for the differential promoter activities of $G S T A 1^{*} A$ and $G S T A 1^{*} B$, expression of $G S T A 1^{*} A$ being greater than $G S T A 1^{*} B$.

Busulfan pharmacokinetics properties are highly variable among patients and dosing regimens are affected by patients' characteristics such as body weight, age and genotype [16]. For instance, busulfan pharmacokinetics in children differs largely from that observed in adults as clearance decreases with age even when expressed relative to body weight or body surface area [17]. Notably, busulfan is a lipophilic molecule with highly variable absorption and bioavailability [18]. The drug is highly protein bound and extensively metabolized in the liver with less than $2 \%$ being excreted unchanged in the urine $[19,20]$. Busulfan is mainly metabolized through conjugation with glutathione by the major hepatic isoform GSTA1. In vitro experiments showed that two other isoenzymes, GSTM1 and GSTP1, contribute to a lesser extent in the formation of busulfan glutathione conjugates (46\% and $18 \%$ of GSTA1 busulfan activity, respectively) [19]. At this time, the relevance of GSTA1 polymorphisms on busulfan pharmacokinetics in adults, following oral administration, has been suggested but not clearly established [16,21-25].

The primary objective of our study was to investigate the influence of GSTA1 gene variants on busulfan oral clearance in adult patients. Our secondary objective was to combine use of genetic information and AUCs calculated from various limited sampling models (LSM) to characterize the predictive value of these joint strategies for required oral busulfan dose.

\section{Methods}

This is a quasi-experimental retrospective study. De-identified pharmacokinetic data generated in the context of a standard of care procedure was collected from adult patients who underwent HSCT preparation at Maisonneuve-Rosemont hospital over a 4-year period. The research protocol was approved by the ethics committee of Maisonneuve-Rosemont hospital (No. 06068; 5 October 2006).

\subsection{Clinical Study Design}

Adult patients $(n=119)$ aged 18 years and older receiving an oral dose of busulfan $4 \mathrm{mg} / \mathrm{kg} / \mathrm{d}$ (using ideal body weight) divided into 4 doses per day for 4 days (total of 16 doses) were included in this study. Patients were excluded if they vomited in the hour following administration of the first dose. Patients who vomited and who required the administration of additional busulfan tablets were also excluded. Patients were also excluded if a complete pharmacokinetic profile could not be generated or if a DNA sample for genotype determination could not be obtained (e.g., patient's refusal to participate in Maisonneuve-Rosemont DNA banking for research purposes). A total of 97 pharmacokinetic profiles were obtained following the first administration of busulfan or after the second dose for 3 patients (therapeutic monitoring could not be performed on the first dose and standard dose was administered on first and second dose). Standard therapeutic drug monitoring consisted of obtaining 10 blood samples drawn at $0,20,40,60,90,120,180,240,300$ and $360 \mathrm{~min}$ following the first busulfan dose on 
day one. Additional therapeutic drug monitoring was performed on subsequent doses in patients for whom the dose of busulfan was modified based on their pharmacokinetic profile (target AUC at Maisonneuve-Rosemont hospital = 1150-1450 $\mu \mathrm{mol} \cdot \mathrm{min} / \mathrm{L} ; 283,245-357,140 \mathrm{ng} \cdot \mathrm{min} / \mathrm{mL}$ ).

\subsection{Pharmacokinetic Profile Determination}

Pharmacokinetic profiles were obtained by reviewing medical charts. Busulfan plasma levels were determined by a validated HPLC assay with UV detection [26]. The drug concentration-time data were analyzed by standard noncompartmental methods using WinNonLin ${ }^{\circledR} 10.0$ software (Certara, Mountain View, CA, USA) to determine $\mathrm{AUC}_{0 \rightarrow \infty}$ (considered as the reference AUC). Apparent oral clearance (CLo) of busulfan was calculated as $\mathrm{CL} / \mathrm{F}=\operatorname{Dose}_{(\text {oral })} / \mathrm{AUC}_{0 \rightarrow \infty}$ (oral).

\subsection{Genotyping Procedure}

GSTA $A 1$ C $<-69>T$ polymorphism was determined by polymerase chain reaction-restriction fragment length polymorphism as described by Kusama et al. with minor modifications. [24] A 821 bp fragment in the promoter region of the GSTA1 gene was amplified with a forward primer (F: $5^{\prime}$-CCC TAC ATG GTA TAG GTG AAA T-3') and reverse primer (R: 5'-GTG CTA AGG ACA CAT ATT AGC-3'). PCR reactions were performed in a PTC-100 Thermal Cycler (MJ Research Inc., Watertown, MA, USA) under the following conditions: an initial 5 min denaturation step at $95^{\circ} \mathrm{C}$, followed by 35 cycles of $1 \mathrm{~min}$ for each step i.e., denaturation at $96^{\circ} \mathrm{C}$, annealing at $63^{\circ} \mathrm{C}$ and extension at $72{ }^{\circ} \mathrm{C}$, and a final extension step at $72{ }^{\circ} \mathrm{C}$ for $5 \mathrm{~min}$. PCR products were digested with $\mathrm{Hinf} \mathrm{I}$ for $3-4 \mathrm{~h}$ at $37^{\circ} \mathrm{C}$ and separated by electrophoresis ( $100 \mathrm{~V}, 45 \mathrm{~min}$ ) on a $2 \%$ agarose/Synergel.

\subsection{Validation Cohort}

Genotyping procedures for GSTA1 were also performed in random samples $(n=116)$ obtained from a genetic bank constituted of isolated DNA samples provided by a group of individuals (18-25 years old) without known cardiovascular diseases. These analyses were performed to establish GSTA1 allele frequencies in "young heathy" adults. Consent was obtained from each individual prior to participation in this DNA banking initiative.

\subsection{Comparison of the Standard Sampling Strategy to LSMs}

We compared results of the standard sampling model to LSMs. From our previous paper, we have determined that the Bullock 4 limited sampling model as well as the New 4.2 and the New 4.3 LSM would be ideal for this study [5,6]. The Bullock 4 LSM requires blood samples at $0.5,1,4$, and $6 \mathrm{~h}$ after the first dose whereas the New 4.2 LSM require blood samples at 1, 1.5, 3, and $6 \mathrm{~h}$ after the first dose while New 4.3 LSM requires blood samples at 1, 2, 4 and $6 \mathrm{~h}$ post-dose.

\subsection{Statistical Analyses}

Data are expressed as mean \pm SD. The AUCs and oral clearance of busulfan were compared across the genotype groups of GSTA1 using non-parametric tests. Tukey correction was used to determine the $p$ values for multiple comparisons. The allele and genotype frequencies, and Hardy-Weinberg equilibrium were analyzed. Statistical analyses were performed using GraphPad v7.05 (GraphPad Software, Inc., San Diego, CA, USA).

\section{Results}

Over the four-year period of our study, 119 patients received oral busulfan. Therapeutic monitoring was performed on the first (or second dose, $n=3$ ) of busulfan. A total of 100 pharmacokinetic profiles were obtained from those patients' medical charts. Genetic analyses were performed in 89 patients of which two patients were excluded (DNA quality). The characteristics of the 87 patients included in our final analysis are presented in Table 1 . Fifty-five percent (55\%) of these patients were male. Mean age 
was $48.3 \pm 9.7$ (range 25-65) years, adjusted body weight was $65.2 \pm 10$ (range 46-88) kg, and their lean body weight was $63.3 \pm 9.6(44-84) \mathrm{kg}$. Acetaminophen, which could decrease glutathione reserve, was co-administered in 23 patients. Antifungals such as voriconazole and fluconazole but not itraconazole (which has been associated with a decrease in busulfan clearance) were co-administered in six patients ( $n=1$ and 5, respectively). The mean initial dose of busulfan administered was $65 \mathrm{mg}$ and the mean population AUC was 358,066 $\mathrm{ng} \cdot \mathrm{min} / \mathrm{mL}$.

Table 1. Patient demographics.

\begin{tabular}{|c|c|c|c|c|}
\hline \multirow{2}{*}{ Variable } & \multicolumn{3}{|c|}{ GSTA1 Genotype Groups } & \multirow[t]{2}{*}{$p$-Value } \\
\hline & ${ }^{*} A^{*} A$ & ${ }^{*} A{ }^{*} B$ & ${ }^{*} B{ }^{*} B$ & \\
\hline Age: Years \pm SD (range) & $50 \pm 11(27-65)$ & $48 \pm 9(27-63)$ & $48 \pm 10(25-60)$ & 0.8 \\
\hline Gender: Male/female ( $\%$ male) & $13 / 11(54)$ & $26 / 14(65)$ & 9/14 (39) & 0.4 \\
\hline \multicolumn{5}{|l|}{ Weight $(\mathrm{Kg})$} \\
\hline Real Body Weight & $74 \pm 11$ & $73 \pm 15$ & $76 \pm 19$ & 0.8 \\
\hline Adjusted Ideal Body Weight & $65 \pm 9$ & $66 \pm 11$ & $64 \pm 11$ & 0.7 \\
\hline Lean Body Weight & $64 \pm 9$ & $64 \pm 10$ & $61 \pm 10$ & 0.3 \\
\hline Bilirubin (U/L) & $11 \pm 6$ & $14 \pm 10$ & $10 \pm 5$ & 0.2 \\
\hline AST (U/L) & $22 \pm 10$ & $24 \pm 9$ & $22 \pm 11$ & 0.7 \\
\hline ALT (U/L) & $27 \pm 22$ & $34 \pm 23$ & $33 \pm 34$ & 0.5 \\
\hline Albumin $(\mathrm{g} / \mathrm{L})$ & $41 \pm 4$ & $42 \pm 3$ & $43 \pm 5$ & 0.3 \\
\hline Alkaline Phosphatase (U/L) & $95 \pm 38$ & $86 \pm 36^{*}$ & $81 \pm 23$ & 0.01 \\
\hline $\mathrm{LDH}(\mathrm{U} / \mathrm{L})$ & $280 \pm 285^{*}$ & $166 \pm 59$ & $169 \pm 43$ & 0.01 \\
\hline $\begin{array}{l}\text { Previously received } \\
\text { chemotherapy }(\%)\end{array}$ & $22(92)$ & $35(88)$ & $19(83)$ & 0.2 \\
\hline $\begin{array}{l}\text { Previously received } \\
\text { radiotherapy (\%) }\end{array}$ & $3(13)$ & $4(10)$ & $2(13)$ & 0.8 \\
\hline $\begin{array}{c}\text { Number of patients taking } \\
\text { Acetaminophen }(\%)\end{array}$ & $9(37)$ & $8(20)$ & $6(26)$ & 0.02 \\
\hline $\begin{array}{l}\text { Number of patients taking } \\
\text { Antifungal Drugs (\%) }\end{array}$ & $2(8)$ & $3(7)$ & $1(4)$ & 0.4 \\
\hline First dose administered (mg) & $65 \pm 8$ & $66 \pm 12$ & $65 \pm 14$ & 0.9 \\
\hline
\end{tabular}

* Tukey's multiple comparison analysis, the group $\left({ }^{*}\right)$ was statistically different vs. the 2 other genotype groups.

The genotype frequencies found in our cohort were $27.5 \%(n=24), 45.9 \%(n=40)$, and $26.4 \%(n=23)$ for the $G S T A 1{ }^{*} A /{ }^{*} A,{ }^{*} A /{ }^{*} B$, and ${ }^{*} B /{ }^{*} B$ groups, respectively. These frequencies were in Hardy-Weinberg equilibrium but differ from the distribution of alleles observed in our validation cohort (Table 2); more patients presented with a ${ }^{*} B$ genotype $(26.4 \%)$ compared to young healthy subjects (20\%). Demographic data among GSTA1 genotype groups are presented in Table 1. There was no significant difference observed in most of these parameters among the groups except for alkaline phosphatase (APL) and lactate dehydrogenase (LDH) levels. The difference observed for the LDH results can be explained by outlier values for two individuals in the GSTA1*A*A group. A higher proportion of patients receiving acetaminophen was found in the GSTA1*A*A group. However, there was no statistically significant difference in measured AUC or in the apparent oral clearance of busulfan between acetaminophen users and non-users $(p=0.6)$. 
Table 2. GSTA1 genotype frequencies.

\begin{tabular}{|c|c|c|c|c|}
\hline \multirow{2}{*}{ Patients/Cohort } & \multirow{2}{*}{$n$} & \multicolumn{3}{|c|}{ GSTA1 Genotypes \% (n) } \\
\hline & & ${ }^{*} A^{*} A$ & ${ }^{*} A * B$ & ${ }^{*} B * B$ \\
\hline Adult patients treated at HRM (study population) & 87 & $27.6 \%(24)$ & $46 \%(40)$ & $26.4 \%(23)$ \\
\hline Healthy man subjects (validation cohort) & 116 & $31 \%(36)$ & $49 \%(57)$ & $20 \%(23)$ \\
\hline
\end{tabular}

Pharmacokinetic profiles obtained from patients demonstrated that $33 / 87(38 \%)$ patients reached therapeutic range on the first dose: 12 patients were exhibiting subtherapeutic levels while 42 patients were having supratherapeutic levels. Figure 1 illustrates that higher AUCs were observed in patients with a GSTA1* ${ }^{*} B$ genotype $(395,562 \pm 77,083 \mathrm{ng} / \mathrm{mL} / \mathrm{min})$ compared to $G S T A 1^{*} A{ }^{*} B(357,062 \pm 53,100 \mathrm{ng} / \mathrm{mL} / \mathrm{min})$ and GSTA1* $A{ }^{*} A$ patients $(323,691 \pm 65,906 \mathrm{ng} / \mathrm{mL} / \mathrm{min} ; p<0.001)$. Hence, carriers of GSTA1*B $(n=64)$ were significantly associated with lower busulfan CLo compared to wild-type GSTA1*A: $179 \pm 36$ vs. $207 \pm 47 \mathrm{~mL} / \mathrm{min}(p=0.003)$. Busulfan CLo among the three genotype groups are illustrated in Figure 2: $166 \pm 31,187 \pm 40$ and $207 \pm 47 \mathrm{~mL} / \mathrm{min}$, for $G S T A 1^{*} B{ }^{*} B,{ }^{*} A{ }^{*} B$ and ${ }^{*} A{ }^{*} A$, respectively.

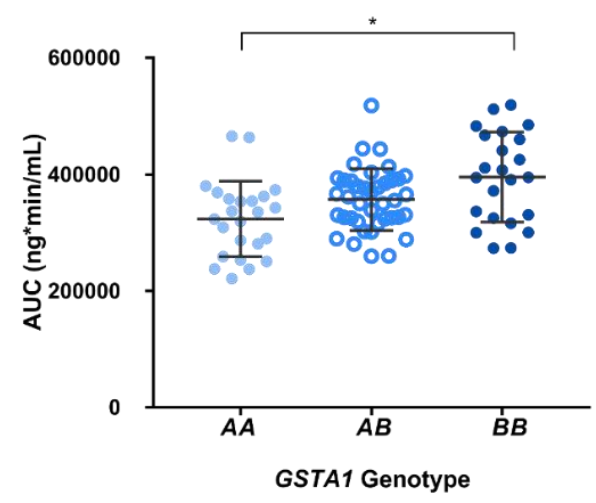

Figure 1. Busulfan plasma concentrations $\left(\mathrm{AUC}_{0-\infty}\right)$ measured after administration of the initial oral $1 \mathrm{mg} / \mathrm{kg}$ dose (1 mg/kg/day, four times a day, for 4 days) observed among the individual GSTA1 genotypes for 89 patients enrolled in this study.

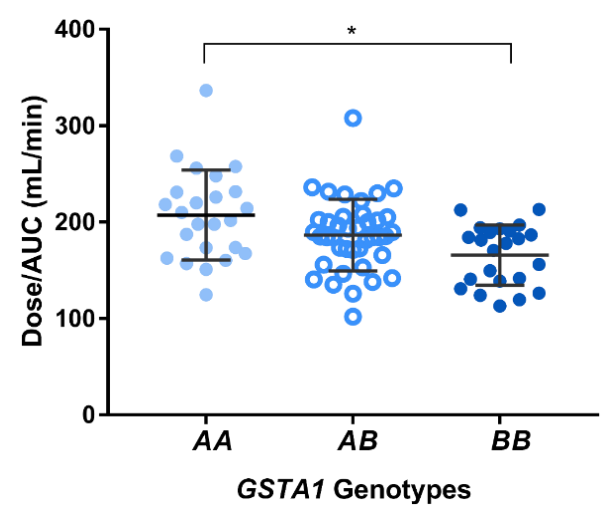

Figure 2. Oral clearance of busulfan calculated after administration of the initial oral dose as a function of patients $(n=89)$ GSTA1 genotypes.

Using the standard AUC method, distribution of patients (\%) above the therapeutic range after the first dose was $29 \%$ for $G S T A 1^{*} A{ }^{*} A, 50 \%$ for ${ }^{*} A{ }^{*} B$ and $65 \%$ for ${ }^{*} B{ }^{*} B$ (Figure 3). Patients with a GSTA1*A ${ }^{*} A$ genotype were more likely to have achieved therapeutic levels (overall $42 \%$ ) after the first dose of treatment compared to subjects with a $G S T A 1^{*} B /{ }^{*} B$ genotype $(26 \%)$. 


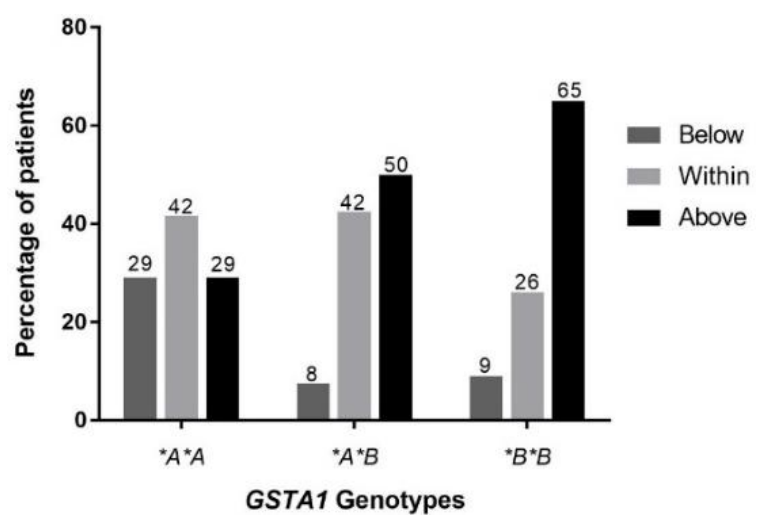

Figure 3. Distribution of patients with an AUC below, within and above the therapeutic range after the initial oral dose of busulfan for each GSTA1 genotype.

The LSMs correctly associated $91 \%$ of patients with their therapeutic level category. In our final patients' cohort $(n=87)$, percent of patients with busulfan mean concentrations in the therapeutic range were $38 \%, 37 \%, 38 \%$ and $41 \%$ for the standard model (AUC with 10 time points), Bullock 4 model, New 4.2 and New 4.3 models, respectively (Supplemental Figure S1). Patients with busulfan mean concentrations above the therapeutic range were $48 \%, 47 \%, 44 \%$ and $44 \%$ for the standard model, Bullock 4 model, New 4.2 and New 4.3 models, respectively. The misclassified patients had a mean difference less than $5 \%\left( \pm 4.8 \%\right.$, range $\left.\mathrm{AUC}_{\mathrm{ref}} / \mathrm{AUC}_{\mathrm{LSM}} 0.89-1.05\right)$ in their AUCs. The proportion of patients and their corresponding therapeutic levels using LSMs is illustrated in Figure 4 for the three GSTA1 genotype groups. The LSMs correctly identified busulfan's AUC above the therapeutic range for individuals carrying GSTA1* $B^{*} B$ genotype for $15 / 15(100 \%)$ using the Bullock 4 model and for 14/15 using New 4.2 and New 4.3 models. The only misclassified patient had a difference of $6 \%$ in the estimated AUCs compared to the standard AUC determination model.
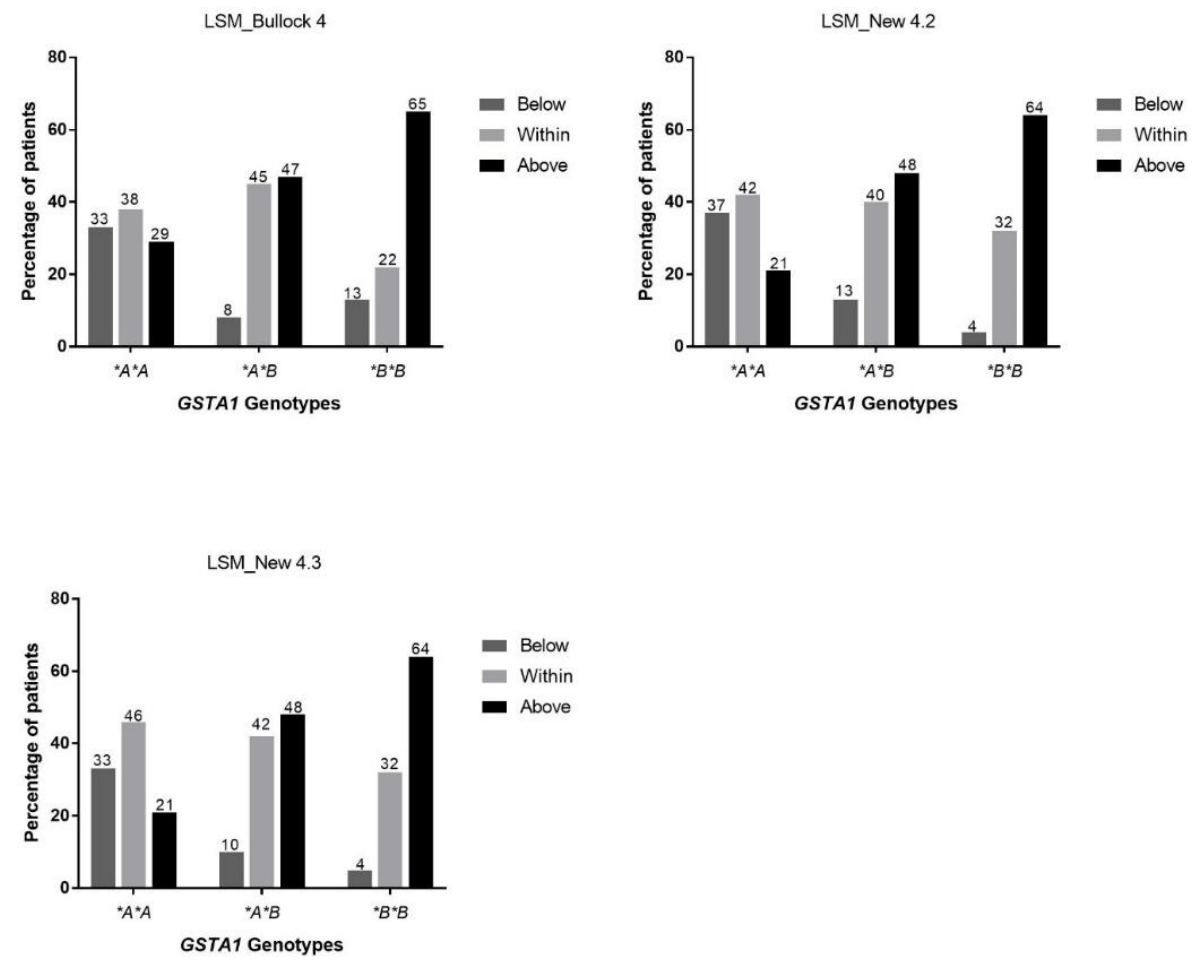

Figure 4. Distribution of patients with an AUC below, within and above the therapeutic range according to their GSTA1 genotype after the first dose of busulfan using 3 limited sampling methods (LSMs) based on 4 blood samples: Bullock 4 , New 4.2 and New 4.3 . 


\section{Discussion}

In this study, we demonstrated that the administration of an initial standard oral dose of busulfan ( $1 \mathrm{mg} / \mathrm{kg}$ of a $4 \mathrm{mg} / \mathrm{kg} /$ day regimen) to patients with a GSTA1* $B^{*} B$ genotype was associated with higher plasma concentrations of busulfan and consequently, with lower estimated oral clearance of the drug. More patients with a $G S T A 1^{*} B^{*} B$ genotype were exhibiting mean plasma concentrations above the targeted therapeutic range for busulfan after the initial dose which could predispose them to increased toxicity from the drug. We also demonstrated that patients from the various GSTA1 genotypes could be efficiently classified for their therapeutic level status by limited sampling strategies using four blood samples instead of 10 .

Busulfan pharmacokinetics has been the subject of intense research due to important inter-subject variability and its narrow therapeutic index $[2,3,16]$. Clinical consequences of inappropriate dosing are well established with significant loss of efficacy in patients with sub-therapeutic levels and toxicity in patients with supra-therapeutic levels of the drug [2]. Various determinants of busulfan pharmacokinetics have been identified including weight, age and genetics. Dosing based on lean body weight and dose adjustment with age are well established [17]. However, the role of genetic polymorphisms still remains to be confirmed.

In the early 1960s, it was established that busulfan spontaneously reacts with glutathione and that conjugation with glutathione is the primary route of elimination $[27,28]$. Studies conducted with various purified human liver GST isoforms established that the highest busulfan-conjugating activity was observed with GSTA1 [19]. Genetic studies described the genomic organization of the human GST gene cluster and characterized the functional activity of genetic polymorphisms in the GSTA1 promoter region $[14,15]$. From these studies, hypotheses were generated suggesting that decreased functional activity associated with the GSTA1*B allele would result in a decreased clearance of busulfan.

In 2006, Kusama et al., investigated for the first time the role of GSTA1 polymorphisms on busulfan pharmacokinetics in a series of 12 patients [24]. Their results demonstrated that the heterozygous group $\left(G S T A 1^{*} A^{*} B ; n=3\right)$ had lower oral clearance, prolonged elimination half-life and higher plasma levels than the wildtype individuals $\left(G S T A 1^{*} A{ }^{*} A ; n=9\right)$. One year later, Kim et al. reported on the first association between GSTA1 polymorphisms and response to busulfan therapy. [29] To date, very few studies have reexamined the role of GSTA1 polymorphisms on busulfan pharmacokinetics after oral administration in adult patients. The study by Abbasi et al. reported on a decrease in busulfan clearance in their $G S T A 1^{*} B^{*} B$ patients' group treated with oral busulfan while Bremer et al. reported on increased averaged concentration and steady-state (Css) in GSTA1* ${ }^{*} B$ patients $[21,25]$. The magnitude of changes in busulfan oral clearance observed in our study $(20 \%)$ in patients with a GSTA1* $B{ }^{*} B$ genotype compared to $G S T^{*} A{ }^{*} A$ patients agrees with these results.

The role of GSTA1 polymorphisms in adults and in children as well as the impact of polymorphisms on other GST isoforms (GSTM1 or GSTP1) on busulfan disposition, effects or toxicity are still controversial [16,21-23,25,30-39]. For instance, Rocha et al. established an association between GSTP1 and chronic graft vs. host disease but Goekkurt et al. did not observe any correlation between various GST polymorphisms and liver toxicity $[30,33]$. Following intravenous administration, ten Brink et al., Kim et al. and Choi et al., found a decrease in busulfan clearance ranging from about $12-15 \%$ in expresser of the GSTA1*B allele while Abbasi et al. found no association $[16,23,25,40]$.

One important observation of our study was that $2 / 3$ of the patients with a GSTA1* $B^{*} B$ genotype had mean plasma levels above the upper limit of the therapeutic range $(357,140 \mathrm{ng} \cdot \mathrm{min} / \mathrm{mL})$ after the first oral dose of busulfan $(442,711 \pm 46,830 \mathrm{ng} \cdot \mathrm{min} / \mathrm{mL})$. A $23 \%$ decrease in their subsequent oral doses was required to achieve therapeutic levels. Similar results were observed by Abbasi et al. in their GSTA1 ${ }^{*} B$ patients where a $20 \%$ decrease in dose was required between Dose 1 and 5 in order to achieve therapeutic levels [25].

The frequency of the GSTA1*B* $B$ observed in our validation healthy subject cohort $(20 \%)$ was almost identical to the one observed in two other Caucasian populations (20 and $20.8 \%$, respectively) [41,42]. In our adult study cohort receiving busulfan, the ${ }^{*} B$ variant was found in slightly higher frequency 
( $26 \%$ for the ${ }^{*} B * B$ genotype). An increased frequency of GSTA1* $B^{*} B$ expressers was also observed in other Caucasian patients' population $[15,43,44]$. The significance of these observations would need to be confirmed in larger studies.

Finally, we have reported previously on the value of limited sampling strategies (four blood samples) to estimate mean plasma levels of patients undergoing treatment with oral busulfan [5]. This type of approach is of great relevance in sparing blood in patients with leukemia or other blood-related diseases. Bullock et al. also reported very similar results using slightly different time points (4) to calculate AUC [6].

\section{Conclusions}

Our study suggests that genetic polymorphisms associated with GSTA1 explain a significant part of the variability observed for busulfan pharmacokinetics. Our data support the utility of busulfan LSMs strategy clinically and for the interpretation of pharmacogenetics results.

Supplementary Materials: The following are available online at http://www.mdpi.com/1999-4923/11/9/440/s1, Figure S1. Percentage of patients with an AUC below, within and above the therapeutic range after the initial oral dose of busulfan using the refence AUC vs. 3 limited sampling methods (LSMs) based on 4 blood samples: Bullock 4, New 4.2 and New 4.3.

Author Contributions: Conceptualization, V.M., B.V., M.F. and J.T.; data collection, P.B., S.B. and K.A.; methodology development and validation, F.B. and B.P.; data analysis, M.T., P.B., S.B., K.A. and V.M.; writing-original draft preparation, M.T., V.M.; writing-review and editing, V.M. and J.T.; visualization, V.M.; supervision, V.M project administration, V.M. and J.T.; funding acquisition, V.M. and J.T.

Funding: Supported by internal funding obtained from the University of Montreal. Veronique Michaud was the recipient of a research scholarship from Fonds de Recherche du Québec-Santé (FRQS) in partnership with the Institut National d'Excellence en Santé et en Services Sociaux (INESSS).

Conflicts of Interest: The authors declare no conflict of interest.

\section{References}

1. Ben-Barouch, S.; Cohen, O.; Vidal, L.; Avivi, I.; Ram, R. Busulfan fludarabine vs busulfan cyclophosphamide as a preparative regimen before allogeneic hematopoietic cell transplantation: Systematic review and meta-analysis. Bone Marrow Transpl. 2016, 51, 232-240. [CrossRef] [PubMed]

2. Krivoy, N.; Hoffer, E.; Lurie, Y.; Bentur, Y.; Rowe, J.M. Busulfan use in hematopoietic stem cell transplantation: Pharmacology, dose adjustment, safety and efficacy in adults and children. Curr. Drug Saf. 2008, 3, 60-66. [CrossRef] [PubMed]

3. Russell, J.A.; Kangarloo, S.B. Therapeutic drug monitoring of busulfan in transplantation. Curr. Pharm. Des. 2008, 14, 1936-1949. [CrossRef] [PubMed]

4. Schuler, U.; Schroer, S.; Kuhnle, A.; Blanz, J.; Mewes, K.; Kumbier, I.; Proksch, B.; Zeller, K.P.; Ehninger, G. Busulfan pharmacokinetics in bone marrow transplant patients: Is drug monitoring warranted? Bone Marrow Transpl. 1994, 14, 759-765.

5. Bouchard, P.; Bilodeau, S.; Alain, K.; Vadnais, B.; Franco, M.; Turgeon, J.; Michaud, V. Evaluation of Limited Sampling Methods for Oral Busulfan Pharmacokinetic Monitoring in Adult Patients Undergoing Hematopoietic Stem Cell Transplantation. Ther. Drug Monit. 2016, 38, 414-418. [CrossRef]

6. Bullock, J.M.; Smith, P.F.; Booker, B.M.; Loughner, J.; Capozzi, D.; McCarthy, P.L., Jr.; Shaw, L.M. Development of a pharmacokinetic and Bayesian optimal sampling model for individualization of oral busulfan in hematopoietic stem cell transplantation. Ther. Drug Monit. 2006, 28, 62-66. [CrossRef] [PubMed]

7. Chattergoon, D.S.; Saunders, E.F.; Klein, J.; Calderwood, S.; Doyle, J.; Freedman, M.H.; Koren, G. An improved limited sampling method for individualised busulphan dosing in bone marrow transplantation in children. Bone Marrow Transpl. 1997, 20, 347-354. [CrossRef]

8. Hassan, M.; Fasth, A.; Gerritsen, B.; Haraldsson, A.; Syruckova, Z.; van den Berg, H.; Sandstrom, M.; Karlsson, M.; Kumlien, S.; Vossen, J. Busulphan kinetics and limited sampling model in children with leukemia and inherited disorders. Bone Marrow Transpl. 1996, 18, 843-850. 
9. Balasubramanian, P.; Chandy, M.; Krishnamoorthy, R.; Srivastava, A. Evaluation of existing limited sampling models for busulfan kinetics in children with beta thalassaemia major undergoing bone marrow transplantation. Bone Marrow Transpl. 2001, 28, 821-825. [CrossRef]

10. Allocati, N.; Masulli, M.; Di Ilio, C.; Federici, L. Glutathione transferases: Substrates, inihibitors and pro-drugs in cancer and neurodegenerative diseases. Oncogenesis 2018, 7, 8. [CrossRef]

11. Nissar, S.; Sameer, A.; Chowdri, N.; Rashid, F. Glutathione S Transferases: Biochemistry, Polymorphism and Role in Colorectal Carcinogenesis. J. Carcinog. Mutagenesis 2017, 8, 286. [CrossRef]

12. Coles, B.F.; Kadlubar, F.F. Human alpha class glutathione S-transferases: Genetic polymorphism, expression, and susceptibility to disease. Methods Enzymol. 2005, 401, 9-42. [PubMed]

13. Available online: https://www.proteinatlas.org/ENSG00000243955-GSTA1/tissue (accessed on 8 July 2019).

14. Morel, F.; Rauch, C.; Coles, B.; Le Ferrec, E.; Guillouzo, A. The human glutathione transferase alpha locus: Genomic organization of the gene cluster and functional characterization of the genetic polymorphism in the hGSTA1 promoter. Pharmacogenetics 2002, 12, 277-286. [CrossRef] [PubMed]

15. Coles, B.F.; Morel, F.; Rauch, C.; Huber, W.W.; Yang, M.; Teitel, C.H.; Green, B.; Lang, N.P.; Kadlubar, F.F. Effect of polymorphism in the human glutathione S-transferase A1 promoter on hepatic GSTA1 and GSTA2 expression. Pharmacogenetics 2001, 11, 663-669. [CrossRef] [PubMed]

16. Choi, B.; Kim, M.G.; Han, N.; Kim, T.; Ji, E.; Park, S.; Kim, I.W.; Oh, J.M. Population pharmacokinetics and pharmacodynamics of busulfan with GSTA1 polymorphisms in patients undergoing allogeneic hematopoietic stem cell transplantation. Pharmacogenomics 2015, 16, 1585-1594. [CrossRef] [PubMed]

17. Hoffer, E.; Akria, L.; Tabak, A.; Scherb, I.; Rowe, J.M.; Krivoy, N. A simple approximation for busulfan dose adjustment in adult patients undergoing bone marrow transplantation. Ther. Drug Monit. 2004, 26, 331-335. [CrossRef]

18. Sjoo, F.; El-Serafi, I.; Enestig, J.; Mattsson, J.; Liwing, J.; Hassan, M. Comparison of algorithms for oral busulphan area under the concentration-time curve limited sampling estimate. Clin. Drug Investig. 2014, 34, 43-52. [CrossRef] [PubMed]

19. Czerwinski, M.; Gibbs, J.P.; Slattery, J.T. Busulfan conjugation by glutathione S-transferases alpha, mu, and pi. Drug Metab. Dispos. 1996, 24, 1015-1019.

20. Wu, X.; Xie, H.; Lin, W.; Yang, T.; Li, N.; Lin, S.; Yuan, X.; Ren, J.; Li, X.; Huang, X. Population pharmacokinetics analysis of intravenous busulfan in Chinese patients undergoing hematopoietic stem cell transplantation. Clin. Exp. Pharmacol. Physiol. 2017, 44, 529-538. [CrossRef]

21. Bremer, S.; Floisand, Y.; Brinch, L.; Gedde-Dahl, T.; Bergan, S. Glutathione Transferase Gene Variants Influence Busulfan Pharmacokinetics and Outcome After Myeloablative Conditioning. Ther. Drug Monit. 2015, 37, 493-500. [CrossRef]

22. Ten Brink, M.H.; Swen, J.J.; Bohringer, S.; Wessels, J.A.; van der Straaten, T.; Marijt, E.W.; von dem Borne, P.A.; Zwaveling, J.; Guchelaar, H.J. Exploratory analysis of 1936 SNPs in ADME genes for association with busulfan clearance in adult hematopoietic stem cell recipients. Pharm. Genom. 2013, 23, 675-683. [CrossRef] [PubMed]

23. Ten Brink, M.H.; Wessels, J.A.; den Hartigh, J.; van der Straaten, T.; von dem Borne, P.A.; Guchelaar, H.J.; Zwaveling, J. Effect of genetic polymorphisms in genes encoding GST isoenzymes on BU pharmacokinetics in adult patients undergoing hematopoietic SCT. Bone Marrow Transpl. 2012, 47, 190-195. [CrossRef] [PubMed]

24. Kusama, M.; Kubota, T.; Matsukura, Y.; Matsuno, K.; Ogawa, S.; Kanda, Y.; Iga, T. Influence of glutathione S-transferase A1 polymorphism on the pharmacokinetics of busulfan. Clin. Chim. Acta. 2006, 368, 93-98. [CrossRef] [PubMed]

25. Abbasi, N.; Vadnais, B.; Knutson, J.A.; Blough, D.K.; Kelly, E.J.; O’Donnell, P.V.; Deeg, H.J.; Pawlikowski, M.A.; Ho, R.J.; McCune, J.S. Pharmacogenetics of intravenous and oral busulfan in hematopoietic cell transplant recipients. J. Clin. Pharmacol. 2011, 51, 1429-1438. [CrossRef] [PubMed]

26. Rifai, N.; Sakamoto, M.; Lafi, M.; Guinan, E. Measurement of plasma busulfan concentration by high-performance liquid chromatography with ultraviolet detection. Ther. Drug Monit. 1997, 19, 169-174. [CrossRef] [PubMed]

27. Roberts, J.J.; Warwick, G.P. The mode of action of alkylating agents. II. Studies of the metabolism of myleran. The reaction of myleran with some naturally occurring thiols in vitro. Biochem. Pharmacol. 1961, 6, 205-216. [CrossRef] 
28. Roberts, J.J.; Warwick, G.P. The mode of action of alkylating agents-III: The formation of 3-hydroxytetrahydrothiophene-1:1-dioxide from 1:4-dimethanesulphonyloxybutane (Myleran), S- $\beta$-1alanyltetrahydrothiophenium mesylate, tetrahydro-thiophene and tetrahydrothiophene-1:1-dioxide in the rat, rabbit and mouse. Biochem. Pharmacol. 1961, 6, 217-220.

29. Kim, I.; Keam, B.; Lee, K.H.; Kim, J.H.; Oh, S.Y.; Ra, E.K.; Yoon, S.S.; Park, S.S.; Kim, C.S.; Park, S.; et al. Glutathione S-transferase A1 polymorphisms and acute graft-vs.-host disease in HLA-matched sibling allogeneic hematopoietic stem cell transplantation. Clin. Transpl. 2007, 21, 207-213. [CrossRef] [PubMed]

30. Goekkurt, E.; Stoehlmacher, J.; Stueber, C.; Wolschke, C.; Eiermann, T.; Iacobelli, S.; Zander, A.R.; Ehninger, G.; Kroger, N. Pharmacogenetic analysis of liver toxicity after busulfan/cyclophosphamide-based allogeneic hematopoietic stem cell transplantation. Anticancer Res. 2007, 27, 4377-4380. [PubMed]

31. Johnson, L.; Orchard, P.J.; Baker, K.S.; Brundage, R.; Cao, Q.; Wang, X.; Langer, E.; Farag-El Maasah, S.; Ross, J.A.; Remmel, R.; et al. Glutathione S-transferase A1 genetic variants reduce busulfan clearance in children undergoing hematopoietic cell transplantation. J. Clin. Pharmacol. 2008, 48, 1052-1062. [CrossRef]

32. Zwaveling, J.; Press, R.R.; Bredius, R.G.; van Derstraaten, T.R.; den Hartigh, J.; Bartelink, I.H.; Boelens, J.J.; Guchelaar, H.J. Glutathione S-transferase polymorphisms are not associated with population pharmacokinetic parameters of busulfan in pediatric patients. Ther. Drug Monit. 2008, 30, 504-510. [CrossRef] [PubMed]

33. Rocha, V.; Porcher, R.; Fernandes, J.F.; Filion, A.; Bittencourt, H.; Silva, W., Jr.; Vilela, G.; Zanette, D.L.; Ferry, C.; Larghero, J.; et al. Association of drug metabolism gene polymorphisms with toxicities, graft-versus-host disease and survival after HLA-identical sibling hematopoietic stem cell transplantation for patients with leukemia. Leukemia 2009, 23, 545-556. [CrossRef] [PubMed]

34. Elhasid, R.; Krivoy, N.; Rowe, J.M.; Sprecher, E.; Adler, L.; Elkin, H.; Efrati, E. Influence of glutathione S-transferase A1, P1, M1, T1 polymorphisms on oral busulfan pharmacokinetics in children with congenital hemoglobinopathies undergoing hematopoietic stem cell transplantation. Pediatr. Blood Cancer 2010, 55, 1172-1179. [CrossRef] [PubMed]

35. Krivoy, N.; Zuckerman, T.; Elkin, H.; Froymovich, L.; Rowe, J.M.; Efrati, E. Pharmacokinetic and pharmacogenetic analysis of oral busulfan in stem cell transplantation: Prediction of poor drug metabolism to prevent drug toxicity. Curr. Drug Saf. 2012, 7, 211-217. [CrossRef] [PubMed]

36. Ten Brink, M.H.; van Bavel, T.; Swen, J.J.; van der Straaten, T.; Bredius, R.G.; Lankester, A.C.; Zwaveling, J.; Guchelaar, H.J. Effect of genetic variants GSTA1 and CYP39A1 and age on busulfan clearance in pediatric patients undergoing hematopoietic stem cell transplantation. Pharmacogenomics 2013, 14, 1683-1690. [CrossRef] [PubMed]

37. Ansari, M.; Rezgui, M.A.; Theoret, Y.; Uppugunduri, C.R.; Mezziani, S.; Vachon, M.F.; Desjean, C.; Rousseau, J.; Labuda, M.; Przybyla, C.; et al. Glutathione S-transferase gene variations influence BU pharmacokinetics and outcome of hematopoietic SCT in pediatric patients. Bone Marrow Transpl. 2013, 48, 939-946. [CrossRef]

38. Yin, J.; Xiao, Y.; Zheng, H.; Zhang, Y.C. Once-daily i.v. BU-based conditioning regimen before allogeneic hematopoietic SCT: A study of influence of GST gene polymorphisms on BU pharmacokinetics and clinical outcomes in Chinese patients. Bone Marrow Transpl. 2015, 50, 696-705. [CrossRef]

39. Huezo-Diaz Curtis, P.; Uppugunduri, C.R.S.; Muthukumaran, J.; Rezgui, M.A.; Peters, C.; Bader, P.; Duval, M.; Bittencourt, H.; Krajinovic, M.; Ansari, M. Association of CTH variant with sinusoidal obstruction syndrome in children receiving intravenous busulfan and cyclophosphamide before hematopoietic stem cell transplantation. Pharm. J. 2018, 18, 64-69. [CrossRef]

40. Kim, S.D.; Lee, J.H.; Hur, E.H.; Lee, J.H.; Kim, D.Y.; Lim, S.N.; Choi, Y.; Lim, H.S.; Bae, K.S.; Noh, G.J.; et al. Influence of GST gene polymorphisms on the clearance of intravenous busulfan in adult patients undergoing hematopoietic cell transplantation. Biol. Blood Marrow Transpl. 2011, 17, 1222-1230. [CrossRef]

41. Skrzypczak-Zielinska, M.; Zakerska-Banaszak, O.; Tamowicz, B.; Sobieraj, I.; Drweska-Matelska, N.; Szalata, M.; Slomski, R.; Mikstacki, A. Polymorphisms and allele frequencies of glutathione S-transferases A1 and P1 genes in the Polish population. Genet. Mol. Res. 2015, 14, 2850-2859. [CrossRef]

42. Bredschneider, M.; Klein, K.; Murdter, T.E.; Marx, C.; Eichelbaum, M.; Nussler, A.K.; Neuhaus, P.; Zanger, U.M.; Schwab, M. Genetic polymorphisms of glutathione S-transferase A1, the major glutathione S-transferase in human liver: Consequences for enzyme expression and busulfan conjugation. Clin. Pharmacol. Ther. 2002, 71, 479-487. [CrossRef] [PubMed] 
43. Suvakov, S.; Damjanovic, T.; Stefanovic, A.; Pekmezovic, T.; Savic-Radojevic, A.; Pljesa-Ercegovac, M.; Matic, M.; Djukic, T.; Coric, V.; Jakovljevic, J.; et al. Glutathione S-transferase A1, M1, P1 and T1 null or low-activity genotypes are associated with enhanced oxidative damage among haemodialysis patients. Nephrol. Dial. Transpl. 2013, 28, 202-212. [CrossRef] [PubMed]

44. Spalletta, G.; Piras, F.; Gravina, P.; Bello, M.L.; Bernardini, S.; Caltagirone, C. Glutathione S-transferase alpha 1 risk polymorphism and increased bilateral thalamus mean diffusivity in schizophrenia. Psychiatry Res. 2012, 203, 180-183. [CrossRef] [PubMed]

(C) 2019 by the authors. Licensee MDPI, Basel, Switzerland. This article is an open access article distributed under the terms and conditions of the Creative Commons Attribution (CC BY) license (http://creativecommons.org/licenses/by/4.0/). 